\title{
Increasing doses of fiber do not influence short-term satiety or food intake and are inconsistently linked to gut hormone levels
}

\author{
Holly J. Willis', William Thomas², Alison L. Eldridge ${ }^{3}$, \\ Laura Harkness ${ }^{4}$, Hilary Green ${ }^{3}$ and Joanne L. Slavin ${ }^{1} *$ \\ 'Department of Food Science and Nutrition, University of Minnesota, St. Paul, MN, USA; ${ }^{2}$ Division of Biostatistics, \\ School of Public Health, University of Minnesota, Minneapolis, MN, USA; ${ }^{3}$ Nestlé Research Center, Lausanne, \\ Switzerland; ${ }^{4}$ Nestlé Inc., Solon, OH, USA
}

\section{Abstract}

Background: People who eat more fiber often have a lower body weight than people who eat less fiber. The mechanism for this relationship has been explained, in part, by increased satiety, which may occur as a result of changes in appetite-suppressing gut hormone levels, and decreases in food intake at subsequent meals.

Objective: We hypothesized that increasing doses of mixed fiber, consumed in muffins for breakfast, would proportionally influence satiety, gut hormone levels, and subsequent food intake.

Design: This was a randomized, double-blind, crossover study. Healthy men $(n=10)$ and women $(n=10)$ with a BMI of $24 \pm 2$ (mean \pm SEM) participated in this study. Fasting subjects consumed a muffin with $0,4,8$, or $12 \mathrm{~g}$ of mixed fibers and approximately $500 \mathrm{kcal}$. Visual analog scales rated hunger and satiety for $3 \mathrm{~h}$; blood was drawn to measure ghrelin, glucagon-like peptide-1 (GLP-1), and peptide $\mathrm{YY}_{3-36}\left(\mathrm{PYY}_{3-36}\right)$ at various intervals; and food intake was measured at an ad libitum lunch.

Results: Responses to satiety-related questions did not differ among treatments. However, despite lack of differences in satiety, gut hormone levels differed among treatments. Ghrelin was higher after the $12 \mathrm{~g}$ fiber dose than after the 4 and $8 \mathrm{~g}$ fiber doses. GLP-1 was higher after the $0 \mathrm{~g}$ fiber dose than after the 12 and $4 \mathrm{~g}$ fiber doses, and $\mathrm{PYY}_{3-36}$ did not differ among fiber doses. Food intake was also indistinguishable among doses.

Conclusion: Satiety, gut hormone response, and food intake did not change in a dose-dependent manner after subjects consumed $0,4,8$, and $12 \mathrm{~g}$ of mixed fiber in muffins for breakfast.

Keywords: fiber dose; fiber; ghrelin; GLP-1; PYY; appetite; hunger; visual analog scales

Received: I2 March 20I0; Revised: 26 May 20I0; Accepted: II June 2010; Published: 29 June 2010

$\mathrm{O}$ bservational studies suggest that fiber intake is inversely associated with body weight (1-3). For example, a study reported that in a 20 -month period, every $1 \mathrm{~g}$ increase in total fiber consumed per day, decreased body weight by $0.25 \mathrm{~kg}$ (4). Improved satiety and decreased food intake are common theories used to describe why fiber intake may be associated with a lower body weight (5).

Fiber has well-documented effects on satiety (6); and because of this, it is often implied that consuming highfiber foods will reduce food intake. Some studies have compared satiety and food intake after one dose of fiber compared to a control; however, few, if any, studies have evaluated how increasing doses of fiber actually influence food intake at subsequent meals.

Certain types of fiber may influence satiety more than others (7). For example, a large review suggests that viscous fibers, such as guar gum, pectin, and $\beta$-glucan may improve satiety more than less viscous fibers (6).

Gut hormones are also proposed as important factors for the control of appetite and satiety (8). Ghrelin has been shown to be positively correlated with hunger (9), while glucagon-like peptide-1 (GLP-1) and peptide $\mathrm{YY}_{3-36}\left(\mathrm{PYY}_{3-36}\right)$ are believed to be inversely correlated 
(10, 11). However, most studies evaluate gut hormone changes after predominantly carbohydrate, protein, or fat intake; very few studies have evaluated how these three hormones change in response to fiber intake $(12,13)$. It is possible, that fiber decreases appetite by favorably influencing gut hormone levels.

At a time when food manufactures are adding fibers to everything from yogurt to snack foods, it is important to know more about the physiologic benefits of various fiber types and doses. Therefore, we hypothesized that a mixed-fiber muffin, fed at four practical doses $(0,4,8$, and $12 \mathrm{~g}$ ), would increase satiety and decrease food intake in a dose-dependent manner. We also hypothesized that ghrelin, GLP-1, and $\mathrm{PYY}_{3-36}$ would change in proportion to fiber dose.

\section{Methods and materials}

The University of Minnesota Institutional Review Board Human Subjects Committee approved all aspects of this research. Twenty subjects were recruited in the fall of 2007 by flyers placed around the University of Minnesota campus. They were chosen based on power calculations ( $80 \%$ power with $\alpha=0.05$ ) calculated from the differences in visual analog scale (VAS) scores.

Subjects were screened over the phone and subject eligibility was determined in accordance with all inclusion and exclusion criteria. Included subjects were Englishspeaking, healthy men and women between 18 and 65 years of age. They were non-smoking; not taking medications; non-dieting (weight stable over last 3 months); had a BMI between 18 and 27; and were normoglycemic. Subjects also had to be able to give blood through an IV. Subjects were excluded if they: did not regularly consume breakfast; had a distaste for muffins; had any history of disease or significant past medical history; were vegetarians or consumed more than approximately $15 \mathrm{~g}$ of fiber per day; were pregnant or lactating; or if they had irregular menstrual cycles.

\section{Screening and study visits}

Prior to any procedures the study coordinator obtained a signature on informed consent. After formal acceptance into the study, each subject received instructions for the day before study visits. In the $24 \mathrm{~h}$ prior to each visit, subjects followed a low-fiber, lead-in diet, which prohibited use of fiber supplements and alcohol. Subjects were required to maintain their body weight and activity level throughout the study period; specifically, they had to avoid excessive exercise $24 \mathrm{~h}$ before each visit.

Fasted subjects arrived at the General Clinical Research Center (GCRC) on the University of Minnesota campus between 7:00 and 9:00 am on weekdays. All visits were held in a quiet room, which allowed subjects to read, use laptops, work quietly, or listen to music. Visits were scheduled at least 1 week apart. However, women participated only during the follicular phase of their menstrual cycle so some visits were more than a week apart.

Upon arrival at the GCRC, a registered nurse inserted an antecubital IV that was used for blood drawing purposes only. The IV was left in place for $10 \mathrm{~min}$ before drawing the baseline blood sample; this was done in attempt to reduce the possibility of elevated hormone levels after venipuncture stress (14).

After $10 \mathrm{~min}$ of rest, subjects were given instructions for completing the computerized VAS and proceeded to complete their baseline appetite assessment. Immediately after, fasting blood samples were drawn to evaluate ghrelin, GLP-1, and PYY $3-36$. Subjects then consumed either a low-fiber control muffin or one of three fibercontaining muffins for breakfast. The muffin and $250 \mathrm{ml}$ of water were consumed within $10 \mathrm{~min}$.

Appetite sensations were rated by VAS at 15, 30, 45, 60, 90,120 , and $180 \mathrm{~min}$ after baseline. Ghrelin samples were drawn at 15, 30, 60, and $90 \mathrm{~min}$, and GLP-1 and PYY $3-36$ were drawn at 30 and $60 \mathrm{~min}$. The IV was removed at the end of the 180-min period and subjects were given a buffet lunch of pre-selected, pre-weighed pizzas, and 11 of water. Subjects were told to eat until comfortably satisfied. After $30 \mathrm{~min}$, the remaining pizza and water were weighed, and energy intakes were calculated. Pizza has been successfully used as an ad libitum meal in previous studies (15-17). Before subjects were discharged from the GCRC they were instructed to keep a detailed food record for the remainder of the day.

\section{Treatment muffins}

In a randomized fashion subjects received the four treatment muffins containing: $0,4,8$, and $12 \mathrm{~g}$ of mixed fiber for breakfast. The mixed fiber was presented in equal proportions in each muffin: pectin (Apple Pectin SF 50-LV, Herbstreith \& Fox, Neuenbürg/Württ, Germany), barley $\beta$-glucan (Barliv, Cargill, Hammond, IN), guar gum (Guar, TIC Gums, White Marsh, MD), pea fiber (Centara Dietary Pea Fibre, Norben, Willoughby, OH), and citrus fiber (Citri-Fi 100FG, Fibrestar, Inc., Willmar, MN). These fibers were chosen based on a literature review of fiber and satiety, which suggested that viscous fibers were more likely to affect appetite, and for their ability to be baked uniformly into muffins (6). The muffins were spice flavored and commercially made (Nestlé R\&D Center; Solon, OH). Attempts were made to balance macronutrient content; however, disguising viscous fiber in products is extremely difficult and some variances in macronutrient content were inevitable (Table 1).

After baking and cooling, the muffins were frozen at $-20^{\circ} \mathrm{C}$. Muffins were removed from the freezer $2 \mathrm{~h}$ before each subject visit and were thawed at room temperature. 
Table 1. Composition of treatment muffins ${ }^{\mathrm{a}}$

\begin{tabular}{|c|c|c|c|c|c|c|c|c|c|c|}
\hline $\begin{array}{l}\text { Mixed fiber } \\
\text { dose }(g)\end{array}$ & $\begin{array}{c}\text { Total } \\
\text { fiber }(g)\end{array}$ & $\begin{array}{l}\text { Soluble } \\
\text { fiber }(g)\end{array}$ & $\begin{array}{l}\text { Insoluble } \\
\text { fiber }(g)\end{array}$ & kcal & $\begin{array}{l}\text { Total } \\
\text { fat }(g)\end{array}$ & $\begin{array}{c}\text { Total } \\
\text { carbohydrate (g) }\end{array}$ & Protein $(\mathrm{g})$ & $\begin{array}{l}\text { Moisture } \\
\text { content (g) }\end{array}$ & Ash (g) & $\begin{array}{l}\text { Serving } \\
\text { size }(g)\end{array}$ \\
\hline 0 & $<1$ & $\mathrm{n} / \mathrm{a}$ & $\mathrm{n} / \mathrm{a}$ & 502 & 19.5 & 74 & 11 & 24 & I & 144 \\
\hline 4 & 5.7 & 2.5 & 3.2 & 488 & 13 & 81 & 12 & 68 & 3 & 176 \\
\hline 8 & 8.9 & 4.0 & 4.9 & 493 & 10 & 89 & 12 & 62 & 3 & 175 \\
\hline 12 & 12.8 & 6.1 & 6.7 & 544 & 13 & 93 & 13 & 81 & 3 & 204 \\
\hline
\end{tabular}

${ }^{a}$ Content listed per serving. Fiber, fat, protein, moisture, and ash analyses were determined by AOAC Methodology. Carbohydrate and calorie content were estimated by US Department of Agriculture calculations. Fiber was assigned $0 \mathrm{kcal} / \mathrm{g}$ in the calculations. This analysis was completed at Covance Labs, Madison, WI, USA.

\section{Visual analog scales (VAS)}

Questions were taken directly from previously validated $100 \mathrm{~mm}$ VAS (18). The appetite-related questions assessed hunger, satisfaction, fullness, and prospective food intake.

\section{Dietary intake analysis}

The post-intervention food records were analyzed using the dietary analysis program, Nutrition Data System for Research (NDSR, version 2007, Nutrition Coordinating Center, Minneapolis, MN). NDSR provided detailed nutrient information, including: total energy, carbohydrate, fat, protein, and fiber intake.

\section{Sample collection and analysis}

Gut hormones were analyzed with commercially available RIA and ELISA kits from Millipore, St. Charles, MO (Total Ghrelin, Cat. \# GHRT-89HK; Active GlucagonLike Peptide-1, Cat. \# EGLP-35K; and Human PYY $3-36$, Cat. \# PYY-67HK). Plasma samples were prepared and stored according to manufacturer's instructions. Intra- and inter-assay coefficients of variation are available on the manufacturer website.

\section{Statistical analysis}

Every subject who consented to the study completed all four visits. Appetite-related responses and gut hormone levels are expressed as change from baseline and were compared using area under the curve (AUC). AUC was calculated by the trapezoidal rule. Change from baseline AUC for appetite questions; change from baseline AUC for gut hormones; and ad libitum food intake in the postintervention period were compared among treatments using a mixed effects linear model with a random subject effect (Proc Mixed). Proc Mixed calculated treatment means, standard error, and statistical differences between treatment means. Data are presented as mean $\pm \mathrm{SE}$ when appropriate. Statistical significance was determined at $p<0.05$. Carryover, treatment sequence, and interaction terms were tested in each model, but were omitted because they were not significant at $p<0.05$. All final models included fiber dose and visit number only. Spearman correlation coefficient tests were performed to assess associations between select variables. All analyses were carried out with SAS 9.1.2 (SAS Institute, Cary, NC).

\section{Results}

\section{Subject characteristics}

Twenty racially diverse subjects (10 men and 10 women) participated in this study. The mean age and BMI were $26 \pm 7$ years and $24 \pm 2 \mathrm{~kg} / \mathrm{m}^{2}$, respectively. Age and BMI did not differ between genders or among the treatment sequence groups (data not shown).

Baseline responses on VAS and fasting gut hormone levels were not statistically different among treatments. All data were normally distributed and, therefore, were not transformed.

\section{Appetite sensations}

AUC hunger and prospective food intake did not differ among fiber doses; AUC satisfaction and fullness varied slightly among treatments (Fig. 1). Subjects were more satisfied and more full after consuming the $4 \mathrm{~g}$ fiber muffin than after consuming the $0 \mathrm{~g}$ fiber muffin $(p<0.01)$; the remaining treatments were indistinguishable. Appetite sensations did not change in a clear dosedependent manner ( $p$ for trends $>0.11$ ).

\section{Food intake}

Food intake at the lunch buffet and in the post-intervention period did not differ among fiber doses (Fig. 2). Total fiber $(\mathrm{g})$, total fat $(\mathrm{g})$, total carbohydrate $(\mathrm{g})$, total protein $(\mathrm{g})$, and total food weight $(\mathrm{g})$ consumed were also indistinguishable (data not shown).

\section{Gut hormones}

AUC ghrelin was higher after the $12 \mathrm{~g}$ fiber dose than after the 4 and $8 \mathrm{~g}$ fiber doses (Fig. 3). This was unexpected since ghrelin is known to be the hunger 

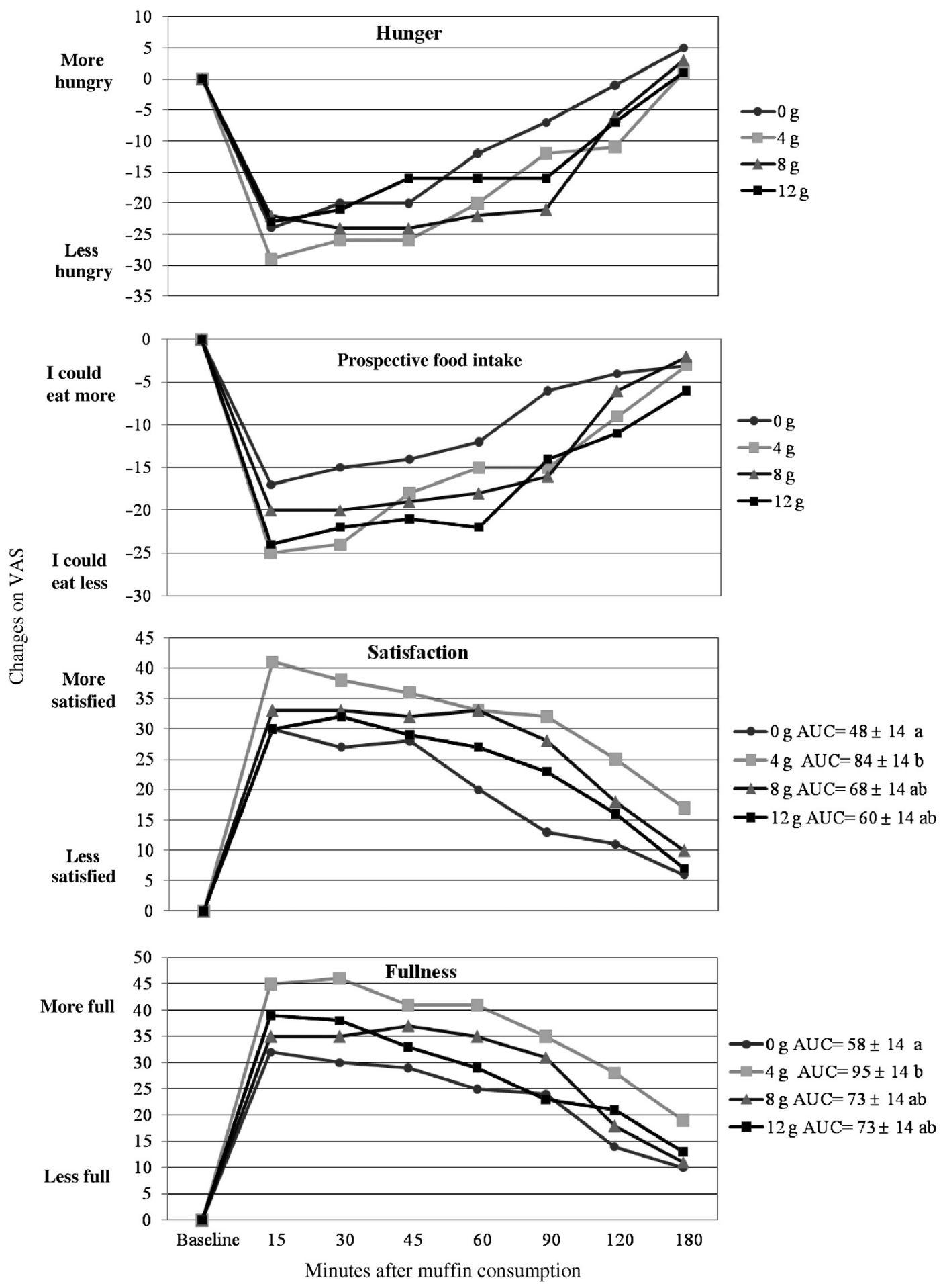

Fig. 1. AUC changes for satiety-related questions (expressed as change from baseline). In the legend, the numbers after each fiber dose represent the AUC score \pm SEM. The treatments with different letters have statistically different AUC; $p<0.05$. AUC is not specified unless the fiber doses provoked significantly different responses.

hormone and our subjective appetite measures indicated that there were no differences in hunger among the 4 fiber doses. In addition, AUC ghrelin did not correlate with AUC hunger for any of the fiber doses (Spearman Correlation Coefficients; $p>0.05)$. Ghrelin did not change in a clear dose-dependent manner ( $p$ for trend $=0.24$ ).

AUC GLP-1 was higher after the $0 \mathrm{~g}$ fiber dose than after the 4 and $12 \mathrm{~g}$ doses; it was also higher after the $8 \mathrm{~g}$ dose than after the $12 \mathrm{~g}$ dose (Fig. 4). GLP-1 did 


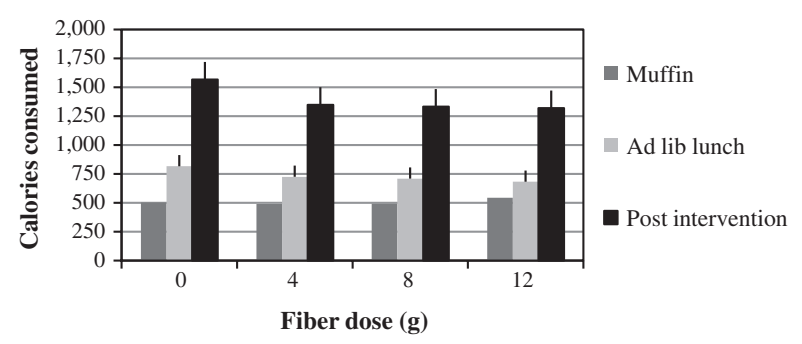

Fig. 2. Mean ( \pm SEM) calorie intake during 24-h intervention day. There were no statistical differences among treatments for intake at the lunch buffet or during the post-intervention period.

not change in a clear dose-dependent manner ( $p$ for trend $=0.08)$.

AUC PYY P-36 did not differ among treatments, but approximately $65 \%$ of samples fell below the assay detection level of $21.1 \mathrm{pg} / \mathrm{ml}$ (data not shown). Levels less than detection were included in the analysis as $21 \mathrm{pg} / \mathrm{ml}$.

\section{Discussion}

The purpose of this study was to compare the effects of four practical doses of mixed fiber on satiety, gut hormone levels, and food intake. Surprisingly, none of our endpoints changed in a dose-dependent manner.

Our findings are inconsistent with previous reviews suggesting that fiber intake is positively associated with satiety $(5,6)$. To the best of our knowledge, only two crossover studies have evaluated how various doses of the same fiber influence satiety in the same subject population. In each of these studies, the higher fiber dose was more satiating than the low- or no-fiber dose. Mathern et al. (19) studied the effects of 0,4 , and $8 \mathrm{~g}$ of viscous fenugreek fiber on a variety of appetite sensations. They found that $8 \mathrm{~g}$ of fenugreek mixed into orange juice was significantly more satiating than 0 or $4 \mathrm{~g}$. Similarly, Gustafsson et al. (20) found that portions of carrots containing 6 and $9 \mathrm{~g}$ of fiber were significantly more satiating than portions containing $3 \mathrm{~g}$ of fiber, when incorporated into a mixed meal. It is difficult to explain

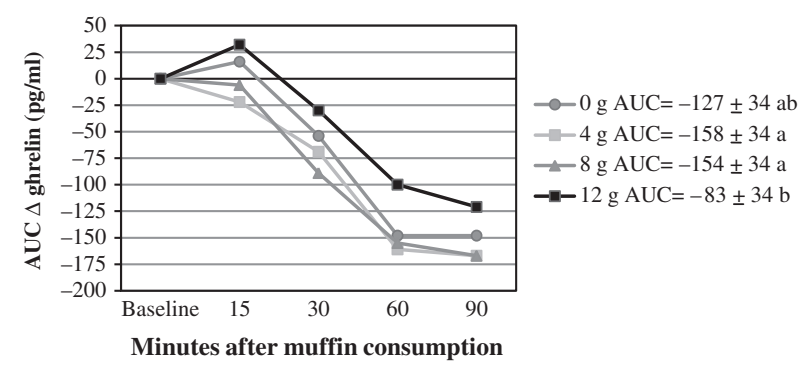

Fig. 3. AUC ghrelin (expressed as change from baseline). In the legend, the numbers after each fiber dose represent the AUC score \pm SEM. The treatments with different letters have statistically different AUC; $p<0.05$.

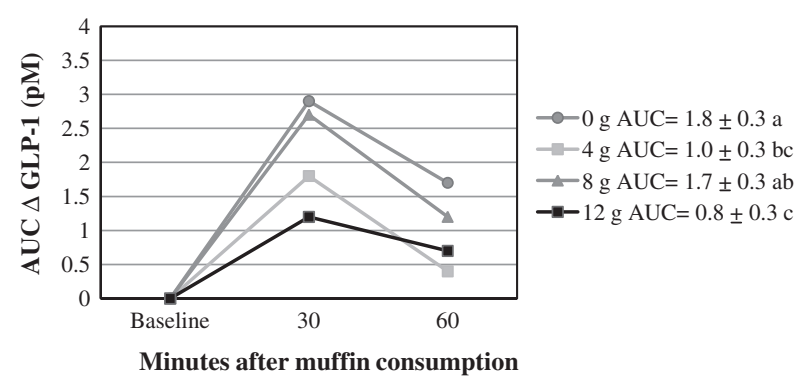

Fig. 4. AUC GLP-1 (expressed as change from baseline). In the legend, the numbers after each fiber dose represent the AUC score \pm SEM. The treatments with different letters have statistically different AUC; $p<0.05$.

why our results are incongruous with these two studies; however, it is likely related to the type of fiber administered. Certain types of fiber have been found to be more satiating than others (7). The fibers used in this study were chosen because of their viscous characteristics and their previous association with appetite suppression (6). Our results, however, suggest that a combination of fibers may not be as effective as one fiber given in isolation.

Studies that use lower doses of fiber generally find no effect on satiety. For example, Mattes et al. (21) found no difference in satiety when subjects consumed a snack bar with $4 \mathrm{~g}$ of mixed fiber and a bar with $1 \mathrm{~g}$ of fiber. Similarly, Hlebowicz et al. (22) found no differences in appetite ratings after subjects consumed a control cereal and cereals with $1.5-7 \mathrm{~g}$ of fiber. Lastly, a third study found snack bars with 4-10 g of added fiber had no influence on appetitive sensations compared to a $2 \mathrm{~g}$ fiber control (23). Although, our study included up to $12 \mathrm{~g}$ of fiber, it is possible that this dose still was not large enough to influence appetite. Collectively, the results of these studies suggest that higher fiber doses may be needed to induce satiety.

It should also be noted that the water content increased and the caloric density decreased slightly with each dose of fiber. It is possible that these differences could have influenced our satiety results. However, this is unlikely since research suggests that an increased water content and increased caloric density should improve satiety (6); and this was not the case in our study. In fact, the $12 \mathrm{~g}$ fiber muffin (with the highest water content and lowest caloric density) was no more satiating than any of the other muffins. Also of note, we recognize that the $0 \mathrm{~g}$ fiber muffin contained more fat than the other muffins. We do not, however, feel this influenced our findings since the satiety-related results for this muffin were not significantly different from the other muffins with less fat.

A large dietary fiber review reported that subjects tend to eat less at subsequent meals (and over time) if they are fed higher fiber foods compared to lower fiber foods (5). Our data contradict this association. Food intake at the 
ad libitum pizza lunch, and in the post-intervention period, was indistinguishable among our fiber doses. This, however, was somewhat expected since appetite sensations were not significantly different among our fiber doses. If subjects' hunger and prospective food intake levels were not different then we would not expect food intake to differ at a subsequent meal or for the remainder of the day. Mattes (21) reported similar findings after feeding subjects a combination of viscous fibers in a breakfast bar.

Many reviews have suggested that gut hormones - like ghrelin, GLP-1, and $\mathrm{PYY}_{3-36}$ - play influential roles in appetite regulation and food intake $(8,24-27)$. However, it is clear that different macronutrients exert different post-prandial effects $(28,29)$.

Research suggests that digestible carbohydrates or proteins are more effective for suppressing post-prandial ghrelin than fat $(25,28,30)$. However, the effect of consuming a predominantly fiber food, or consuming fiber as part of a mixed meal, is rarely described.

Elevated ghrelin is typically correlated with hunger and stimulation of food intake, while ghrelin suppression is correlated with satiety $(25,31,32)$. In our study, AUC ghrelin was higher after the $12 \mathrm{~g}$ fiber dose than after the 4 and $8 \mathrm{~g}$ doses. This finding was unexpected, since there were no differences in hunger or satiety among these doses. There is some evidence, however, that fiber intake may inhibit ghrelin suppression. For example, ghrelin suppression was inhibited when comparing meals that had little or no fiber, to meals that contained high doses of psyllium (33), viscous fibers (34), and wheat fiber (35).

It is possible that the viscous nature of our fibers inhibited ghrelin suppression by altering gastric emptying and changing patterns of digestion and absorption (36, 37). However, if this were true then we should have expected to see the most ghrelin suppression after the $0 \mathrm{~g}$ fiber dose, which we did not. Further research is needed to better understand the role ghrelin plays in appetite after fiber intake.

GLP-1 is typically very low in the fasting state, but rises quickly after food intake, especially after carbohydrates (10). The rise of GLP-1 has been correlated with increased satiety and less hunger $(38,39)$. In our study, AUC GLP-1 was highest after the $0 \mathrm{~g}$ fiber treatment and lowest after the $12 \mathrm{~g}$ dose. GLP-1 was also significantly higher after the $0 \mathrm{~g}$ fiber dose than after the $4 \mathrm{~g}$ fiber dose. This is contrary to what we would expect, since the $4 \mathrm{~g}$ fiber dose produced greater feelings of satisfaction and fullness compared to the $0 \mathrm{~g}$ fiber treatment.

Again, we hypothesize that gastric emptying time and overall nutrient absorption may have been slower after our fiber treatments; thus, fewer stimuli (nutrients) were available to promote GLP-1 release. It is conceivable that nutrients interfaced with intestinal cells and nerve fibers more rapidly after the $0 \mathrm{~g}$ fiber dose, which subsequently produced a greater GLP-1 response. This theory is supported by Juvonen et al. (36). They compared highand low-viscosity beverages with equivalent fiber content and found that the high-viscosity beverage significantly slowed gastric emptying and suppressed GLP-1 release compared to the equivalent low-viscosity beverage. Miholic et al. (40) also report that gastric emptying time is positively correlated with GLP-1 levels. Specifically, they state that faster gastric emptying time was related to higher GLP-1 concentrations. This is contrary to the findings of others, who have reported that GLP-1 is inversely associated with gastric emptying time (38, 41, 42). However, these studies have evaluated gastric emptying after GLP-1 infusions or GLP-1 stimulated by fiberfree meals.

Similar to GLP-1, $\mathrm{PYY}_{3-36}$ concentrations are expected to increase shortly after food intake (11). The change in $\mathrm{PYY}_{3-36}$ concentration is believed to reflect calorie content and the macronutrient composition of a meal. However, there are no published human studies evaluating changes in $\mathrm{PYY}_{3-36}$ after fiber is consumed as part of a mixed meal. Several studies have indicated that satiety increases in proportion to plasma levels of $\mathrm{PYY}_{3-36}$; however, this is most often seen after exogenous administration and not by way of endogenous production after food intake (43-45).

$\mathrm{PYY}_{3-36}$ did not rise substantially after any of our muffins were consumed. However, the majority of our subjects' blood samples remained below the assay detection range for $\mathrm{PYY}_{3-36}$. We have no reason to believe this was an assay error, since preparation and analysis techniques were the same as those previously described in the literature $(46,47) . \mathrm{PYY}_{3-36}$ was consistently detectable in seven of our 20 subjects; though, there was significant variability in the baseline values among subjects and among test days (22-161 pg/ml). This suggests that basal levels of $\mathrm{PYY}_{3-36}$ are highly variable within, and between, individuals, and that this study was not powered appropriately to determine statistical differences in $\mathrm{PYY}_{3-36}$.

In conclusion, increasing doses of a practical dose of mixed fiber did not influence satiety, gut hormone levels, or food intake in a dose-dependent manner. Despite common notions that fiber may improve satiety, this does not appear true for all types and doses of fibers. Therefore, blanket statements between fiber and satiety should be made with caution, and should be specific to a particular fiber type and dose. As well, three commonly accepted objective appetite markers (ghrelin, GLP-1, and PYY $\mathrm{P}_{3-36}$ ) were not consistent with the subjective satiety ratings of our subjects. This emphasizes the complexity of appetite and gut hormone signaling in the setting of fiber intake. 


\section{Acknowledgements}

This research was sponsored by the Nestlé Research Center, a Doctoral Dissertation Fellowship from the University of Minnesota, and Grant No. M01 RR00400 from the National Center for Research Resources.

\section{Conflict of interest and funding}

ALE, LH, and HG are employees of Nestlé but have no conflicts of interest. Authors HJW, WT, and JLS have no conflicts of interest.

\section{References}

1. Howarth NC, Saltzman E, McCrory MA, Greenberg AS, Dwyer J, Ausman L, et al. Fermentable and nonfermentable fibre supplements did not alter hunger, satiety or body weight in a pilot study of men and women consuming self-selected diets. J Nutr 2003; 133: 3141-4.

2. Liu S, Willett WC, Manson JE, Hu FB, Rosner B, Colditz G. Relation between changes in intakes of dietary fibre and grain products and changes in weight and development of obesity among middle-aged women. Am J Clin Nutr 2003; 78: 920-7.

3. Maskarinec G, Takata Y, Pagano I, Carlin L, Goodman MT, Le Marchand L, et al. Trends and dietary determinants of overweight and obesity in a multiethnic population. Obesity (Silver Spring) 2006; 14: 717-26.

4. Tucker LA, Thomas KS. Increasing total fibre intake reduces risk of weight and fat gains in women. J Nutr 2009; 139: 576-81.

5. Howarth NC, Saltzman E, Roberts SB. Dietary fibre and weight regulation. Nutr Rev 2001; 59: 129-39.

6. Slavin J, Green H. Dietary fibre and satiety. Nutr Bull 2007; 32: $32-42$.

7. Willis HJ, Eldridge AL, Beiseigel J, Thomas W, Slavin JL. Greater satiety response with resistant starch and corn bran in human subjects. Nutr Res 2009; 29: 100-5.

8. Huda MS, Wilding JP, Pinkney JH. Gut peptides and the regulation of appetite. Obes Rev 2006; 7: 163-82.

9. Kojima M, Kangawa K. Structure and function of ghrelin. Results Probl Cell Differ 2008; 46: 89-115.

10. Holst JJ. The physiology of glucagon-like peptide 1 . Physiol Rev 2007; 87: 1409-39.

11. Neary MT, Batterham RL. Peptide YY: food for thought. Physiol Behav 2009; 97: 616-9.

12. Essah PA, Levy JR, Sistrun SN, Kelly SM, Nestler JE. Effect of macronutrient composition on postprandial peptide YY levels. J Clin Endocrinol Metab 2007; 92: 4052-5.

13. Stock S, Leichner P, Wong AC, Ghatei MA, Kieffer TJ, Bloom SR, et al. Ghrelin, peptide YY, glucose-dependent insulinotropic polypeptide, and hunger responses to a mixed meal in anorexic, obese, and control female adolescents. J Clin Endocrinol Metab 2005; 90: 2161-8.

14. Kawakami Y. Noninvasive methods to monitor the production of hormone. Rinsho Byori 2001; 49: 562-5.

15. Samra RA, Anderson GH. Insoluble cereal fibre reduces appetite and short-term food intake and glycemic response to food consumed 75 min later by healthy men. Am J Clin Nutr 2007; 86: 972-9.

16. Freeland KR, Anderson GH, Wolever TM. Acute effects of dietary fibre and glycaemic carbohydrate on appetite and food intake in healthy males. Appetite 2008; 52: 58-64.

17. Anderson GH, Catherine NL, Woodend DM, Wolever TM. Inverse association between the effect of carbohydrates on blood glucose and subsequent short-term food intake in young men. Am J Clin Nutr 2002; 76: 1023-30.

18. Flint A, Raben A, Blundell JE, Astrup A. Reproducibility, power and validity of visual analogue scales in assessment of appetite sensations in single test meal studies. Int J Obes Relat Metab Disord 2000; 24: 38-48.

19. Mathern JR, Raatz SK, Thomas W, Slavin JL. Effect of fenugreek fibre on satiety, blood glucose and insulin response and energy intake in obese subjects. Phytother Res 2009; 23: 1543-8.

20. Gustafsson K, Asp NG, Hagander B, Nyman M. Dose-response effects of boiled carrots and effects of carrots in lactic acid in mixed meals on glycaemic response and satiety. Eur J Clin Nutr 1994; 48: 386-96.

21. Mattes RD. Effects of a combination fibre system on appetite and energy intake in overweight humans. Physiol Behav 2007; 90: 705-11.

22. Hlebowicz J, Wickenberg J, Fahlstrom R, Bjorgell O, Almer LO, Darwiche G. Effect of commercial breakfast fibre cereals compared with corn flakes on postprandial blood glucose, gastric emptying and satiety in healthy subjects: A randomized blinded crossover trial. Nutr J 2007; 6: 22, http://www.biomedcentral. com/content/pdf/1475-2891-8-26.pdf [cited 10 April 2009].

23. Peters HP, Boers HM, Haddeman E, Melnikov SM, Qvyjt F. No effect of added beta-glucan or of fructooligosaccharide on appetite or energy intake. Am J Clin Nutr 2009; 89: 58-63.

24. Chaudhri OB, Salem V, Murphy KG, Bloom SR. Gastrointestinal satiety signals. Annu Rev Physiol 2008; 70: 239-55.

25. Cummings DE, Overduin J. Gastrointestinal regulation of food intake. J Clin Invest 2007; 117: 13-23.

26. Naslund E, Hellstrom PM. Appetite signaling: from gut peptides and enteric nerves to brain. Physiol Behav 2007; 92: 256-62.

27. Wren AM, Bloom SR. Gut hormones and appetite control. Gastroenterology 2007; 132: 2116-30.

28. Karhunen LJ, Juvonen KR, Huotari A, Purhonen AK, Herzig KH. Effect of protein, fat, carbohydrate and fibre on gastrointestinal peptide release in humans. Regul Pept 2008; 149: $70-8$.

29. Lomenick JP, Melguizo MS, Mitchell SL, Summar ML, Anderson JW. Effects of meals high in carbohydrate, protein, and fat on ghrelin and peptide YY secretion in prepubertal children. J Clin Endocrinol Metab 2009; 94: 4463-71.

30. Baynes KC, Dhillo WS, Bloom SR. Regulation of food intake by gastrointestinal hormones. Curr Opin Gastroenterol 2006; 22: 626-31.

31. Callahan HS, Cummings DE, Pepe MS, Breen PA, Matthys CC, Weigle DS. Postprandial suppression of plasma ghrelin level is proportional to ingested caloric load but does not predict intermeal interval in humans. J Clin Endocrinol Metab 2004; 89: 1319-24.

32. le Roux CW, Patterson M, Vincent RP, Hunt C, Ghatei MA, Bloom SR. Postprandial plasma ghrelin is suppressed proportional to meal calorie content in normal-weight but not obese subjects. J Clin Endocrinol Metab 2005; 90: 1068-71.

33. Karhunen L, Flander S, Liukkonen K-H, Lähteenmäki L, Valtanen S, Jalkanen $\mathrm{H}$, et al. Fibre effectively inhibits postprandial decrease in plasma ghrelin concentration. Obesity Rev 2005; 6: 59 (Presented as a postor at the European Congress on Obesily, Athens, Greece).

34. Mohlig M, Koebnick C, Weickert MO, Lueder W, Otto B, Steiniger J, et al. Arabinoxylan-enriched meal increases serum ghrelin levels in healthy humans. Horm Metab Res 2005; 37: 303-8.

35. Weickert MO, Spranger J, Holst JJ, Otto B, Koebnick C, Mohlig $\mathrm{M}$, et al. Wheat-fibre-induced changes of postprandial peptide 
YY and ghrelin responses are not associated with acute alterations of satiety. Br J Nutr 2006; 96: 795-8.

36. Juvonen KR, Purhonen AK, Salmenkallio-Marttila M, Lahteenmaki L, Laaksonen DE, Herzig KH, et al. Viscosity of oat bran-enriched beverages influences gastrointestinal hormonal responses in healthy humans. J Nutr 2009; 139: $461-6$.

37. Hoad CL, Rayment P, Spiller RC, Marciani L, Alonso Bde C, Traynor $\mathrm{C}$, et al. In vivo imaging of intragastric gelation and its effect on satiety in humans. J Nutr 2004; 134: 2293-300.

38. Naslund E, Barkeling B, King N, Gutniak M, Blundell JE, Holst JJ, et al. Energy intake and appetite are suppressed by glucagon-like peptide-1 (GLP-1) in obese men. Int J Obes Relat Metab Disord 1999; 23: 304-11.

39. Verdich C, Flint A, Gutzwiller JP, Naslund E, Beglinger C, Hellstrom PM, et al. A meta-analysis of the effect of glucagonlike peptide-1 (7-36) amide on ad libitum energy intake in humans. J Clin Endocrinol Metab 2001; 86: 4382-9.

40. Miholic J, Hoffmann M, Holst JJ, Lenglinger J, Mittlbock M, Bergmann $\mathrm{H}$, et al. Gastric emptying of glucose solution and associated plasma concentrations of GLP-1, GIP, and PYY before and after fundoplication. Surg Endosc 2007; 21: 309-14.

41. Flint A, Raben A, Ersboll AK, Holst JJ, Astrup A. The effect of physiological levels of glucagon-like peptide-1 on appetite, gastric emptying, energy and substrate metabolism in obesity. Int J Obes Relat Metab Disord 2001; 25: 781-92.

42. Naslund E, Bogefors J, Skogar S, Gryback P, Jacobsson H, Holst JJ, et al. GLP-1 slows solid gastric emptying and inhibits insulin, glucagon, and PYY release in humans. Am J Physiol 1999; 277: R910-6.
43. Sloth B, Holst JJ, Flint A, Gregersen NT, Astrup A. Effects of $\mathrm{PYY}_{1-36}$ and $\mathrm{PYY}_{3-36}$ on appetite, energy intake, energy expenditure, glucose and fat metabolism in obese and lean subjects. Am J Physiol Endocrinol Metab 2007; 292: E1062-8.

44. Degen L, Oesch S, Casanova M, Graf S, Ketterer S, Drewe J, et al. Effect of peptide $\mathrm{YY}_{3-36}$ on food intake in humans. Gastroenterology 2005; 129: 1430-6.

45. Batterham RL, Cohen MA, Ellis SM, Le Roux CW, Withers DJ, Frost GS, et al. Inhibition of food intake in obese subjects by peptide $\mathrm{YY}_{3-36}$. N Engl J Med 2003; 349: 941-8.

46. Helou N, Obeid O, Azar ST, Hwalla N. Variation of postprandial $\mathrm{PYY}_{3-36}$ response following ingestion of differing macronutrient meals in obese females. Ann Nutr Metab 2008; 52: $188-95$.

47. Rubio IG, Castro G, Zanini AC. Medeiros-Neto G. Oral ingestion of a hydrolyzed gelatin meal in subjects with normal weight and in obese patients: Postprandial effect on circulating gut peptides, glucose and insulin. Eat Weight Disord 2008; 13: $48-53$.

\footnotetext{
*Joanne L. Slavin

Department of Food Science and Nutrition

University of Minnesota

I 334 Eckles Avenue, St. Paul

MN 55108 , USA

Tel: + I 6126247234

Fax: + I 6126255272

Email: jslavin@umn.edu
} 